Kun Flayyuningtyas, FHamdan Fusein Datubara

Pengembangan Media Pembelajaran Interaltif Berbasis

Powerpoint dan lspiring di Android Untuk Meninghathan

Efeltifitas Pembelajaran IPA di Kelas 3 SD

\title{
PENGEMBANGAN MEDIA PEMBELAJARAN INTERAKTIF BERBASIS POWERPOINT DAN ISPRING DI ANDROID UNTUK MENINGKATKAN EFEKTIFITAS PEMBELAJARAN IPA DI KELAS 3 SD
}

\author{
Kun Hayyuningtyas, \\ UIN Walisongo Semarang \\ kunhayyuingtyas@gmail.com \\ Hamdan Husein Batubara \\ UIN Walisongo Semarang \\ huseinbatubara@gmail.com
}

\begin{abstract}
Abstrak
Media interaktif berbasis PowerPoint adalah media pembelajaran kembangan, berisi materi pembelajaran IPA yang dirancang tersistem untuk peserta didik di kelas 3 Madrasah Ibtidaiyah melalui program dasar powerpoint dan dikembangkan dengan ispring, agar kegiatan belajar mengajar dapat lebih efektif dan maksimal meskipun pembelajaran di lakukan tanpa tatap muka atau pembelajaran jarak jauh. Penelitian ini termasuk penelitian dan pengembangan (Research and Development), dengan menggunakan model penelitian ADDIE dari tahap Analyze, Design, Develop, Implement, dan Evaluate (Branch, 2009). yg melalui beberapa tahap yaitu analisis, desain (perancangan), pengembangan, implementasi, dan evaluasi. Uji coba media pembelajaran interaktif didukung dengan penilaian kevalidan tim ahli, dan data angket kevalidan dari para responden yaitu guru guru Madrasah Ibtidaiyah, dan berdasarkan hasil penelitian $76 \%$ media pembelajaran ini layak untuk digunakan. Media pembelajaran ini bebas dari kesalahan konsep, materi yang di muat up to date dan kekinian, materi yang disajikan cukup dalam dan memenuhi kacakupan yang harus ada, refrensi yang digunakan adalah refrensi terkini yang sesuai dengan kurikulum yang berlaku.
\end{abstract}

\section{Kata Kunci: Media Interaktif, Powerpoint, Android.}

\begin{abstract}
PowerPoint-based interactive media is a developmental learning media, containing science learning materials that are systematically designed for students in grade 3 Madrasah Ibtidaiyah through the basic powerpoint program and developed with ispring, so that teaching and learning activities can be more effective and maximal even though learning is done without face to face or face-to-face contact. distance learning. This research includes research and development (Research and Development), using the ADDIE research model from the Analyze, Design, Develop, Implement, and Evaluate stages (Branch, 2009). which goes through several stages, namely analysis, design (design), development, implementation, and evaluation. Interactive learning media trials are supported by a team of expert validity assessments, and validity questionnaire data from respondents, namely
\end{abstract}


Madrasah Ibtidaiyah teachers, and based on research results $76 \%$ of this learning media is feasible to use. This learning media is free from conceptual errors, the material that is loaded is up to date and current, the material presented is quite deep and meets the required scope, the references used are the latest references that are in accordance with the applicable curriculum.

Keywords: Interactive Media, Powerpoint, Android.

\section{PENDAHULUAN}

Pembelajaran online atau dalam jaringan yang lazim disebut pembelajaran daring menjadi solusi agar kegiatan belajar mengajar tetap berlangsung di masa pandemi covid-19 (Anthony S. Fauci, 2020), seiring kenaikan kasus positif covid-19 di Indonesia seperti saat ini (Yuliana, 2020), guru / pengajar harus bisa beradaptasi dan terus berusaha melakukan pengembangan pengembangan media pembelajaran untuk meningkatkan efektifitas pembelajaran, pengembangan media pembelajaran senantiasa dibutuhkan agar guru atau para pendidik dapat beradaptasi menghadapi dunia pendidikan yang dinamis. (Hamdan Husein Batubara, 2021)

Seiring berkembangnya zaman, dan memasuki era digital kekinian ini guru harus sadar akan pentingnya penggunaan media pembelajaran interaktif demi kesuksesan proses kegiatan belajar mengajar bersama peserta didik, setidaknya guru dapat mengoptimalkan alat dan program program yang dimiliki atau disediakan di sekolah, selain mampu menggunakan guru atau pendidik juga harus mampu mengembangkan media yang ada serta menyesuaikan dan menyeimbangkan dengan materi dan juga kurikulum yang sedang di tempuh saat ini. (Hamdan Husein Batubara, 2021)

Media interaktif yang dikembangkan oleh peneliti adalah media interaktif berbasis powerpoint yang kemudian dikembangkan dengan ispring suite untuk mengoptimalkan media pembelajaran, pengembangan media pembelajaran ini melewati beberapa proses, yaitu pembuatan slide power point yang diisi dengan konten materi yaitu pernapasan pada hewan, lalu memberikan tombol tombol sebagai opsi untuk mengklik slide yang diinginkan. (Hamdan Husein Batubara, 2021)

Berdasarkan hasil penelitian terhadap salah satu responden yaitu guru Sekolah dasar menyatakan bahwa media ini membantu peserta didik untuk lebih memiliki interes pada materi yang dipelajari karena menggunakan android, tidak melulu belajar dengan buku, yang tentunya validitas materi tetap diseuaikan dengan kurikulum yang berlaku saat ini yaitu kurikulum dua ribu tiga belas atau Kurtilas, dengan pengembangan media pembelajaran ini guru lebih mudah menyampaikan materi karena murid memiliki ketertarikan terhadap media pembelajaran. (Hamdan Husein Batubara, 2021) 
Penelitian ini menggunakan konsep penelitian $\mathrm{RnD}$, yaitu konsep dasar penelitian dan pengembangan, konsep ini sangat tepat untuk penelitian efektifitas media pembelajaran berbasis powerpoint dan ispring di android, tujuan dari konsep ini yakni peneliti dapat mengembangkan media pembelajaran yang dibuat dalam penelitiannya, pengembangan ini dilakukan dengan tujuan agar media pembelajaran yang di gunakan dapat di kembangkan dan mengalami peningkatan, untuk kepantingan mempermudah kegiatan belajar mengajar dan membuat kegiatan belajar mengajar menjadi lebih bermakna dan tentunya juga efisien. (Hamdan Husein Batubara, 2021)

Konsep dasar ADDIE dalam penelitian ini dilakukan dengan beberapa tahapan diantaranya, analisis, desain, pengembangan, implementasi dan evaluasi. Tahapan analisis adalah tahapan dasar yang dilakukan dalam konsep ADDIE ada tiga aspek penting yang harus dipahami betul oleh pengembang yaitu:

1. Karakteristik individu atau kelompok pengguna, gaya belajar pengguna, aksesibilitas pengguna, dan kemampuan pengguna dalam mengoperasikan, mengembangkan, dan mengoptimalkan media.

2. Dukungan institusi terhadap penggunaan media pembelajaran, sekolah memiliki hak untuk mempertimbangkan atau memilih media pembelajaran yang akan digunakannya dalam kegiatan belajar mengajar.

3. Jenis media yang berpotensi untuk mendukung efektifitas kegiatan belajar mengajar, hal penting mengenai pemilihan media potensial sebagai berikut:

a. Media yang dipilih mendukung tercapainya tujuan dari kegiatan belajar mengajar,

b. Kapabilitas media dalam penyediaan materi,

c. Adanya fitur fitur dalam media yang berkualitas didalamnya. (Hamdan Husein Batubara, 2021)

Tahap perancangan atau desain, pada tahap perancangan ini peneliti merancang pembuatan media pembelajaran khusus untuk materi, agar peserta didik dapat fokus dalam mempelajari materi, media pembelajaran berisi konten materi mengenai pernapasan pada hewan, materi ini diambil dari buku terbitan kementrian pendidikan yang mengacu pada kurikulum duaribu tigabelas yang biasa disebut Kurtilas, media pembelajaran juga berisi gambar gambar yang mendukung peningkatan pemahaman peserta didik terhadap materi yang dipelajarinya. (Hamdan Husein Batubara, 2021)

Tahap pengembangan development, meliputi proses pembuatan media pembelajaran dan langkah pengembangan media pembelajaran dengan dasar saran dari para ahli atau pakar di bidang tersebut. Di proses ini, peneliti sekaligus pengembang media wajib mebuat produk media pembelajaran secara utuh.

Setelah tahap tahap perancangan selesai. Insteumen penelitian ikut andil dalam tahap ini, poin poin instrumen media pembelajaran itu dapat dikembangkan dengan dasar teori teori yang menegaskan syarat syarat media pembelajaran dapat di sebut sebagai 
media yang ideal. Misalnya, pada media pembelajaran yang peneliti kembangkan yaitu media yang berbasis powerPoin yang dikembangkan dengan ispring suite, dinilai dari beberapa aspek yaitu: unsur visual, unsur teks, keterlibatan peserta didik, dan unsur daya tarik. (Hamdan Husein Batubara, 2021)

Proses penerapan, tahap penerapan atau implementasi merupakan tahap uji coba yang dilakukan setelah serangkaian tahap tahap sebelumnyta terlampaui dengan baik terstruktur dan sesuai dengan materi maupun kurikulum yang berlaku, selain itu yang harus diperhatikan adalah keterlibatan para responden dalam observasi untuk keperluan data yang dibutuhkan dalam penelitian. (Hamdan Husein Batubara, 2021)

\section{METODE PENELITIAN}

1. Jenis penelitian

Penelitian yang dilakukan ini termasuk kedalam penelitian Research and Development $(\mathrm{RnD})$. Jenis penelitian ini dirasa sangat tepat untuk penelitian pengembangan media pembelajaran IPA kelas 3 di Madrasah Ibtidaiyah atau tingkat Sekolah Dasar, jenis penilitian (RnD) merupakan klasifikasi penelitian yang ampuh untuk pengembangan atau praktik pengaplikasian media pembelajaran (Nana Syaodih Sukmadinata, 2006: 164).

Penelitian (Rnd) adalah penelitian dan pengembangan yang didalam jenis penelitian ini terdapat langkah-langkah, tahapan atau proses pengembangan suatu produk yang baru ataupun produk yang pernah ada untuk dapat menyempurnakannya, dengan komposisi produk yang mumpuni dan matang. Produk atau media pembelajaran ini dapat berbentuk perangkat lunak, aplikasi dalam kembangan yang berkonten materi pembelajaran, modul, alat pendukung pembelajaran dalam kelas, laboratorium, dan lainlain. Sugiyono (2012: 409)

Jenis penelitian Rnd, penelitian pengembangan ini merupakan model penelitian prosedural, sifat model penelitian ini deskriptif prosedural dan juga menitikberatkan pada langkah langkah pengembangan media yang sedang diproses. Selaras dengan teori Sugiyono (2012: 409), proses pada langkah-langkah pengembangan wajib dilalui agar tercapai tujuan yang diinginkan, berikut langkah yang harus dilalui: a. Tahap, b. Potensi dan masalah, c. Pengumpulan data, d. Desain produk, e. Validasi desain, f. Revisi desain produk, g. Uji coba produk, h. Revisi Produk, i. Uji coba pemakaian produk, j. Revisi produk, k. Revisi masal. 
2. Waktu dan tempat penelitian

Penelitian ini dilakukan pada bulan juni 2021 di Kota Semarang tepatnya di Kecamatan Mijen, penelitian ini dilakukan di tempat tinggal peneliti, dengan menyebar link aplikasi ke beberapa responden dan tim ahli.

3. Subjek penelitian

Subjek dari pebelitian ini adalah 5 guru Madrasah Ibtidaiyah, guru yang menjadi responden mengujicobakan pada peserta didik yang diampunya pada mata pelajaran IPA di Madrasah Ibtidaiyah dan di Sekolah Dasar, para responden mengisi angket validasi setelah menguji media yang dikembangkan oleh pengembang.

4. Prosedur dan langkah langkah penelitian dengan model ADDIE

Prosedur penelitian dengan model ADDIE merupakan prosedur praktis yang tepat untuk penelitian yang sedang dilakukan saat ini, karena itu berikut adalah langkah langkah penelitian yang dilakukan berdasarkan prosedur dan langkah langkah penelitian dengan model ADDIE:

a. Analisis

1.)Peneliti memeriksa apa saja yang menjadi masalah dan kebutuhan pengguna media yaitu para peserta didik kelas 3 di MI/SD

2.)Menganalisis kebutuhan calon pengguna, dengan research jurnal jurnal, dan membaca realita saat ini peserta didik membutuhkan media pembelajaran yang mendukung efektifitas pembelajaran tanpa tatap muka

3.)Mengidentifikasi jenis jenis media pembelajaran yang berpotensi mendukung efektifitas proses pembelajaran

4.)Peneliti kemudian menulis ide dasar pengembangan media pembelajaran

b. Desain

Produk media pembelajaran ini berbasis powerpoint dan mengembangkannya menggunakan sowtware ispring suite 10 , produk media pembelajaran ini memiliki konten materi pelajaran IPA pernapasan pada hewan.

Produk media pembelajaran ini di desain khusus untuk materi dengan tujuan agar peserta didik dapat lebih fokus dalam pembelajaran yang sedang berlangsung.

c. Pengembangan

1.) Membuat dan membangun produk sesuai dengan rancangan yang di buat, yaitu; membuat slide powerpoint dengan mencantumkan materi pernapasan pada hewan, lalu mengembangkan slide powerpoint menggunakan software ispring suite, kemudian finishing menggunakan website to apk.

2.) Mengembangkan tata cara atau panduan media pembelajaran untuk pendidik dan peserta didik

3.) Menulis instrumen penilaian media pembelajaran, ada dua instrumen yang digunakan dalam penelitian ini yaitu instrumen untuk ahli dan instrumen untuk responden, instrumen untuk responden diberikan kepada lima orang guru 
4.) Meminta penilaian dari tim ahli untuk dapat menguji kevalidan dari produk media pembelajaran yang dibuat

5.) Melakukan revisi sesuai arahan tim ahli, namun pada penelitian ini disayangkan karena waktu yang kurang mengakibatkan kendala revisi, dan produk yang digunakan apa adanya.

d. Implementasi

1.) Persiapan pendidik/pengajar

2.) Persiapan siswa

3.) Uji coba produk

4.) Menggunakan instrument penilain produk

5.) Menilai kompetensi siswa

6.) Melalukan revisi sesuai keperluan

e. Evaluasi

1.) Mengevaluasi respon siswa

2.) Melakukan analisis uji kompetensi siswa

3.) Penyempurnaan produk / finishing

5. Instrument penelitian

Instrumen untuk Ahli Materi

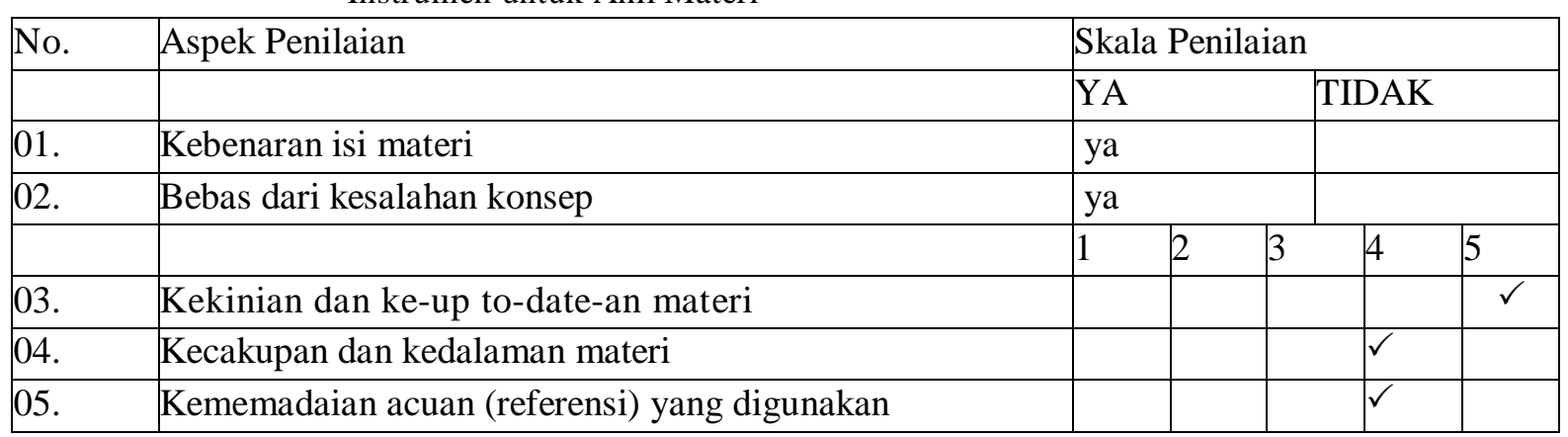

Komentar/Review Tertulis

\begin{tabular}{|l|l|l|l|}
\hline No. & Topik & Sub Topik & Komentar/Review/Rekomendasi \\
\hline & Gambar & $\begin{array}{l}\text { Gambar pada slide } \\
\text { power ponit }\end{array}$ & $\begin{array}{l}\text { Gambar yang disajikan tampak jelas dan } \\
\text { menarik juga yang terpenting sesuai dengan } \\
\text { materi yang dipelajari, yaitu pernapasan pada } \\
\text { hewan. }\end{array}$ \\
& & \\
& & \\
\hline
\end{tabular}


Instrumen responden 1

\begin{tabular}{|l|l|l|l|l|l|l|l|}
\hline No. & Aspek Penilaian & \multicolumn{5}{|l|}{ Skala Penilaian } & \multicolumn{5}{l|}{} \\
\hline & & 1 & 2 & 3 & 4 & 5 \\
\hline & Kemudahan media di gunakan & & & & $\checkmark$ & \\
\hline & Kesesuaian dengan materi pembelajaran & & & & $\checkmark$ & \\
\hline Media pembelajaran mendorong interaksi peserta didik & & & & $\checkmark$ & \\
\hline Font dalam media pembelajaran Nampak jelas & & & $\checkmark$ & & \\
\hline & Kejelasan opsi dalam media pembelajaran & & & & $\checkmark$ & \\
\hline
\end{tabular}

Instrumen responden 2

\begin{tabular}{|l|l|l|l|l|l|l|}
\hline No. & Aspek Penilaian & \multicolumn{5}{|l|}{ Skala Penilaian } \\
\hline & & 1 & 2 & 3 & 4 & 5 \\
\hline & Kemudahan media di gunakan & & & & & $\checkmark$ \\
\hline & Kesesuaian dengan materi pembelajaran & & & & $\checkmark$ & \\
\hline & Media pembelajaran mendorong interaksi peserta didik & & & $\checkmark$ & & \\
\hline & Font dalam media pembelajaran Nampak jelas & & & $\checkmark$ & & \\
\hline & Kejelasan opsi dalam media pembelajaran & & & $\checkmark$ & & \\
\hline
\end{tabular}

Instrumen responden 3

\begin{tabular}{|l|l|l|l|l|l|l|}
\hline No. & Aspek Penilaian & \multicolumn{3}{|l|}{ Skala Penilaian } \\
\hline & & 1 & 2 & 3 & 4 & 5 \\
\hline & Kemudahan media di gunakan & & & & & $\checkmark$ \\
\hline & Kesesuaian dengan materi pembelajaran & & & & $\checkmark$ & \\
\hline & Media pembelajaran mendorong interaksi peserta didik & & $\checkmark$ & & & \\
\hline & Font dalam media pembelajaran Nampak jelas & & & $\checkmark$ & & \\
\hline & Kejelasan opsi dalam media pembelajaran & & & $\checkmark$ & & \\
\hline
\end{tabular}

Instrumen responden 4

\begin{tabular}{|l|l|l|l|l|l|l|}
\hline No. & Aspek Penilaian & \multicolumn{5}{|l|}{ Skala Penilaian } \\
\hline & & 1 & 2 & 3 & 4 & 5 \\
\hline & Kemudahan media di gunakan & & & & & $\checkmark$ \\
\hline & Kesesuaian dengan materi pembelajaran & & & & $\checkmark$ & \\
\hline & Media pembelajaran mendorong interaksi peserta didik & & & & $\checkmark$ & \\
\hline Font dalam media pembelajaran Nampak jelas & & & $\checkmark$ & & \\
\hline & Kejelasan opsi dalam media pembelajaran & & & & & $\checkmark$ \\
\hline
\end{tabular}

Instrumen responden 5

\begin{tabular}{|l|l|l|l|l|l|l|l|}
\hline No. & Aspek Penilaian & \multicolumn{5}{|l|}{ Skala Penilaian } \\
\hline & & 1 & 2 & 3 & 4 & 5 \\
\hline & Kemudahan media di gunakan & & & & & $\checkmark$ \\
\hline & Kesesuaian dengan materi pembelajaran & & & & & $\checkmark$ \\
\hline
\end{tabular}




\begin{tabular}{|l|l|l|l|l|l|l|}
\hline Media pembelajaran mendorong interaksi peserta didik & & & & $\checkmark$ & \\
\hline Font dalam media pembelajaran Nampak jelas & & & $\checkmark$ & & \\
\hline Kejelasan opsi dalam media pembelajaran & & & & $\checkmark$ & \\
\hline
\end{tabular}

\section{HASIL PENELITIAN DAN PEMBAHASAN}

\section{a. Pembahasan}

Pada instrumen oleh ahli materi didapati bahwa media pembelajaran ini : memiliki kebenaran isi mater (materi yang disajikan sesuai dengan kurikulum yang berlaku), media pembelajaran ini bebas dari kesalahan konsep, materi yang di muat up to date dan kekinian, materi yang disajikan cukup dalam dan memenuhi kacakupan yang harus ada, refrensi yang digunakan adalah refrensi terkini yang sesuai dengan kurikulum yang berlaku.

b. Hasil

Pada instrumen responden (guru), dibuktikan bahwa media pembelajaran yang diuji sebagai berikut: $80 \%$ responden sangat menyetujui kemudahan operasional media pembelajaran, $100 \%$ responden menyetujui bahwa materi yang disajikan pada media pembelajaran sesuai, $60 \%$ responded setuju bahwa media pembelajaran tersebut mendorong interaksi peserta didik, $80 \%$ responden setuju font dalam media pembelajaran nampak jelas, $60 \%$ responden setuju bahwa media pembelajaran menampilkan opsi yang jelas untuk pengguna / peserta didik.

\section{KESIMPULAN}

Berdasarkan hasil penelitian dapat disimpulkan bahwa media pembelajaran Media Interaktif Berbasis PowerPoint dan Ispring di Android layak untuk digunakan, melalui penilaian skala kecil yang berjumlah 5 responden didapati bahwa $76 \%$ media layak digunakan.

\section{DAFTAR PUSTAKA}

Achjar, Chalil, dkk. 2008. Pendidikan Berbasis Fitrah. Jakarta: Balai Pustaka

Ali, Mohammad. 2010. Metodologi dan Aplikasi Riset pendidikan. Bandung: Pustaka Cendekia Utama.

Arikunto, Suharsimi, \& Safruddin A.J, Cepi. 2009. Evaluasi Program Pendidikan. Jakarta: Bumi Aksara.

Arikunto, Suharsimi. 1995. Manajemen Penelitian, cet 3. Jakarta: PT Rineka Cipta. 
Kun Flayyuningtyas, Ffamdan Fusein Batubara

Pengembangan Media Pembelajaran Interaltif Berbasis Powerpoint dan lspiring di Android Untuk Meninglatkan Efeltifitas Pembelajaran IPA di Kelas 3 SD

Arikunto, Suharsimi. 2006. Prosedur Penelitian Suatu Pendekatan Praktik. Jakarta: PT Rhineka Cipta.

Arsyad, Azhar. 2011. Media Pembelajaran. Jakarta:PT Raja Grafindo Persada.

Batubara hamdan husein. 2021. Cara mudah membuat media pembelajaran digital. Bandung: PT. Remaja Rosda Karya.

Binanto, Iwan. 2010. Multimedia Digital-Dasar Teori dan Pengembangannya. Yogyakarta:Penerbit Andi.

Daryanto. 2010. Media Pembelajaran. Yogyakarta: Gava Media.

Finkelstein, Ellen, dkk. 2008. Powerpoint for Teachers. San Francisco: Jossey Bass.

Hamalik, Oemar. 2011. Proses Belajar Mengajar. Jakarta: Bumi Aksara.

Indriana, Dina. 2011. Ragam Alat Bantu Media Pengajaran. Yogyakarta: Diva Press. 